\section{Inadequate Preabortion Counseling and Decision Conflict as Predictors of Subsequent Relationship Difficulties and Psychological Stress in Men and Women}

\author{
Catherine T. Coyle, RN, PhD, Priscilla K. Coleman, PhD, Vincent M. \\ Rue, PhD
}

\begin{abstract}
The purpose of this study was to examine associations between perceptions of preabortion counseling adequacy and partner congruence in abortion decisions and two sets of outcome variables involving relationship problems and individual psychological stress. Data were collected through online surveys from 374 women who had a prior abortion and 198 men whose partners had experienced elective abortion. For women, perceptions of preabortion counseling inadequacy predicted relationship problems, symptoms of intrusion, avoidance, and hyperarousal, and meeting full diagnostic criteria for posttraumatic stress disorder (PTSD) with controls for demographic and personal/situational variables used. For men, perceptions of inadequate counseling predicted relationship problems and symptoms of intrusion and avoidance with the same controls used. Incongruence in the decision to abort predicted intrusion and meeting diagnostic criteria for PTSD among women with controls used, whereas for men, decision incongruence predicted intrusion, hyperarousal, meeting diagnostic criteria for PTSD, and relationship problems. Findings suggest that both perceptions of inadequate preabortion counseling and incongruence in the abortion decision with one's partner are related to adverse personal and interpersonal outcomes.
\end{abstract}

\title{
Keywords
}

elective abortion, abortion counseling, abortion decision, relationship problems, psychological stress, PTSD

\section{Introduction}

Few contemporary social issues have evoked more controversy than elective abortion. The continuing debate over abortion and mental health has focused on the nature and frequency of adverse postabortion psychological sequelae. There is now consensus, however, that a significant percentage of women experience negative psychological reactions following abortion (Bradshaw \& Slade, 2003; Coleman, Reardon, Strahan, \& Cougle, 2005; Wilmoth, deAlteriis, \& Bussell, 1992). This study was designed to identify potentially key factors predictive of postabortion relationship problems and psychological stress in both women and men.

\section{Women and Abortion}

Recent studies have corrected methodological weaknesses of earlier studies and have revealed increased mental health risks associated with the experience of abortion. The most thoroughly researched adverse consequences include anxiety, depression, substance abuse, suicidal ideation, and suicide (Broen, Moum, Bodtker, \& Ekeberg, 2004; Coleman et al., 2005; Cougle, Reardon, \& Coleman, 2003; Cougle, Reardon,
Coleman, \& Rue, 2005; Coleman, Reardon, Rue, \& Cougle, 2002; Fergusson, Horwood, \& Ridder, 2006; Gissler, Berg, Bouvier-Colle, \& Buekens, 2005; Gissler, Hemminki, \& Lonnqvist, 1996; Pedersen, 2007, 2008; Reardon \& Cougle, 2002; Reardon, Coleman, \& Cougle, 2004; Reardon et al., 2003; Rees \& Sabia, 2007; Soderberg, Janzon, \& Sojberg, 1998; Thorp, Hartman, \& Shadigan, 2003).

An estimated $43 \%$ of U.S. women will experience at least one anxiety disorder in their lifetime (Breslau, Schultz, \& Peterson, 1995). Posttraumatic stress disorder (PTSD) is a relatively common and particularly disabling anxiety disorder that may be caused by one or more profound stressors. Extensive research has documented how traumatic stress can significantly alter the quality of individuals' lives (Kapfhammer, Rothenhausler, Krauseneck, Stoll, \& Schelling, 2004; Marshall

'APART Inc., Madison, WI, USA

${ }^{2}$ Bowling Green State University, Bowling Green, OH, USA

${ }^{3}$ Institute for Pregnancy Jacksonville, FL, USA

Corresponding Author:

Catherine T. Coyle, APART, Inc., Madison, WI 537I I, USA Email: ctcoyle @charter.net 
et al., 2001; Schnurr, Hayes, Lunney, McFall, \& Uddo, 2006; Warshaw et al., 1993). In the United States, an estimated $13 \%$ of women develop PTSD in their lifetime (Butterfield, Becker, \& Marx, 2002). Systematic exploration of the role of elective abortion as a traumatic stressor associated with symptoms of PTSD has grown substantially in recent years (American Psychological Association, 2008; Bradshaw \& Slade, 2003). Various clinicians have identified abortion as potentially traumagenic (Bagarozzi, 1993, 1994; Burke \& Reardon, 2002; De Puy \& Dovitch, 1997; Speckhard, 1987; Speckhard \& Rue, 1993; Torre-Bueno, 1996). Moreover, recent research has provided empirical evidence of this link between abortion and PTSD symptomatology (Kubany, Hill, \& Owens, 2003; Mufel, Speckhard, \& Sivuha, 2002; Rue, Coleman, Rue, \& Reardon, 2004; Steinberg \& Russo, 2008; Suliman et al., 2007). Rue et al. (2004) and Suliman et al. (2007) reported that $12 \%$ to $18 \%$ of women met the full diagnostic criteria for PTSD after an abortion. An even greater number of women in these studies experienced subthreshold or partial PTSD symptoms following abortion (Barnard, 1990; Rue et al., 2004). The higher the number of these subthreshold symptoms present, the greater the risk of impairment, comorbidity, and suicidal ideation (Marshall et al., 2001).

Informed consent and preprocedure counseling can benefit the patient's decision making and postprocedure emotional and physical adjustment (Baker, Beresford, Halvorson-Boyd, \& Garrity, 1999). The perceived adequacy of preabortion counseling may also play an important role in mitigating or increasing the amount of stress women feel following abortion. Preabortion counseling has been criticized as being too time limited, inadequate to address the ambivalence and the complexity inherent in the abortion decision, lacking in discussion of alternatives to abortion, deficient in assessing coercion or pressure to abort, provided by nonprofessionals who are biased, and not tailored to the needs of the individual patient (Singer, 2004; Steinberg, 1989; Stites, 1982). The National Abortion Federation (2007) advises that "there should be an opportunity for discussion of the patient's feelings about the abortion decision" (p. 3). However, there is no current standard of care in abortion clinics requiring individualized and thorough counseling regarding the patient's feelings and decision making. In a cross-cultural study, Rue et al. (2004) reported that only $29 \%$ of women in the U.S. sample received preabortion counseling, and $84 \%$ stated that it was inadequate.

Individual psychological responses to abortion have also been found to be related to the quality of preabortion decision making and, particularly, lack of partner support for the decision (Bradshaw \& Slade, 2003; Coleman et al., 2005). Research has consistently identified ambivalence and absence of partner support as predictive of negative abortion outcomes (Bracken, 1978; Coleman et al., 2005; Major \& Cozzarelli, 1992; Major et al., 1990; Osofsky \& Osofsky, 1972). Payne, Kravitz, Notman, and Anderson (1976) found that women electing abortion were significantly more angry and depressed afterward, if they were in conflict with their husband or lover over the abortion. Rue et al. (2004) reported that most women were unsure about their decision at the time of the abortion, and only $24 \%$ perceived their partners as supportive. Thus, the degree of perceived partner support and perceived quality of preabortion counseling are seemingly central factors in possible adverse psychological outcomes following elective abortion and they are addressed in this investigation.

\section{Men and Abortion}

Although few studies have addressed men's psychological responses to elective abortion (Coyle, 2007), there are identifiable, recurring themes within the scientific literature. A number of reports have noted men's need and/or desire for counseling (Gordon, 1978; Lauzon, Roger-Achim, Achim, \& Boyer, 2000; Myburgh, Gmeiner, \& van Wyk, 2001a; Rothstein, 1977a; Shostak \& McLouth, 1984). Most men who experience a partner's abortion do not perceive it to be a benign experience (Blumberg, Golbus, \& Hanson, 1975; Gordon \& Kilpatrick, 1977; Poggenpoel \& Myburgh, 2002; Shostak, 1979, 1983; White van-Mourik, Connor, \& Ferguson-Smith, 1992) and specific emotions identified among men include anger, anxiety, guilt, grief, and powerlessness (Gordon \& Kilpatrick, 1977; Holmes, 2004; Mattinson, 1985; Speckhard \& Rue, 1993). In studies of men dealing with therapeutic abortion following amniocentesis, $82 \%$ (Blumberg et al., 1975), 50\% (Jones et al. 1984) and 47\% (White van-Mourik et al. 1992) of men have reported depression. Furthermore, clinicians have observed symptoms among postabortion men that are consistent with delayed or complicated grief reactions and PTSD (Mattinson, 1985; Robson, 2002; Speckhard \& Rue, 1993). These clinical reports involved small numbers of men and, to date, no quantitative studies have looked at the potential for PTSD among men following a partner's abortion. In light of established comorbidity of PTSD with depression and other forms of anxiety (Shalev, 2001), further investigation is warranted to determine the extent of risk of psychological trauma among men whose partners undergo elective abortion.

Men tend to defer the abortion decision to their partners and suppress their own emotions and desires as they attempt to support their partners (Gordon \& Kilpatrick, 1977; Robson, 2002; Shostak \& McLouth, 1984), and men who disagree with their partners' abortion decisions may be more susceptible to intense anger (Naziri, 2007; Reich \& Brindis, 2006). Even men who agree with the abortion decision may suffer from ambivalence (Kero \& Lalos, 2000, 2004; Kero, Lalos, Hogberg, \& Jacobsson, 1999) and their relationships, both social and sexual, with their partners may be strained or come to an end (Berger, 1994; Coleman, Rue, Spence \& Coyle, 2008; Myburgh, Gmeiner, \& van Wyk, 2001b; Naziri, 2007; Rothstein, 1977b; White van-Mourik et al., 1992). 
Although little is known about the long-term effects on men, M. Buchanan and Robbins (1990) provided evidence that adolescent pregnancy resolution may have effects that last into adulthood. These authors found that adult men who experienced abortion during adolescence were more psychologically distressed than adult men who became fathers during adolescence.

Although men are involved with conception and abortion, they are not routinely offered abortion counseling. Despite the call for greater inclusion of and attention to males in abortion clinics (Shostak, 2007), little has changed. Most men who accompany women for abortion do not receive counseling and are left alone to wait.

Given that abortion is a highly personal and sensitive issue, an online investigation seems ideally suited to this topic. Participants may remain anonymous thereby increasing their comfort with self-disclosure. The very existence of an online survey concerning the emotional and relational aspects of abortion may serve to normalize respondents' experiences and encourage them to seek help if needed.

\section{Web-Based Research}

This investigation represents one of the first online studies pertaining to the topic of abortion and, in this section, established advantages and disadvantages of this contemporary data collection mode are examined. Use of the Internet to engage in data collection is time- and cost-efficient (Duffy, 2000; Wilson, 2003), effective in accessing difficult-to-reach populations (Mangan \& Reips, 2007; Yeaworth, 2001), and enhances respondents' comfort with the process and motivation to participate (Adler \& Zarchin, 2002; Gosling, Vazire, Srivastava, \& John, 2004). A review of Web-based studies published in the American Psychological Association journals between 2003 and 2004 (Skitka \& Sargis, 2006) revealed that $21 \%$ of those journals had published at least one such study.

Gosling et al. (2004) compared a large Internet sample with 510 traditional samples and found that Internet samples "are generally more diverse than samples published in a highly selective psychology journal" (p. 99). Similarly, Mathy, Schillace, Coleman, and Berquist (2002) reported their Internet sample as being more representative in terms of education, income, and ethnic diversity than that of a large sample obtained through random digit dialing. Still others have argued that Internet samples are at least as representative as the ubiquitous college-student samples (Gosling et al., 2004; Smith \& Leigh, 1997).

Because data collected through Web-based surveys are often obtained from self-selected, convenience samples, generalization must be approached with caution. However, the voluntary nature of such samples offers considerable benefits (Buchanan \& Smith, 1999; Reips, 2000) such as superior responses in terms of clarity and completeness (Petit, 2002; Walsh, Kiesler, Sproull, \& Hesse, 1992), and responses that are less likely to be contaminated by social desirability (Richman, Kiesler, Weisb, \& Drasgow, 1999). Furthermore, research indicates that data collected online appears to be equivalent to that collected via more traditional methods (Ballard \& Prine, 2002; Hewson \& Charlton, 2005; Knapp \& Kirk, 2003; Robie \& Brown, 2006) and Meyerson and Tryon (2003) concluded that "data collection on the Web is (1) reliable, (2) valid, (3) reasonably representative, (4) cost effective, and (5) efficient" (p. 614).

Potential risks of online survey administration such as inaccurate responses, failure to respond, and the influence of phrasing and ordering of questions are applicable to traditional survey administration methods as well. The risks of multiple survey submissions and nonserious responses (Buchanan \& Smith, 1999; Schmidt 1997) may be avoided by using Internet protocol numbers to identify surveys coming from the same respondent (Birnbaum, 2004; Gosling et al., 2004). Furthermore, the anonymity afforded by the Internet facilitates honest disclosure (Levine, Ancill, \& Roberts, 1989; Locke \& Gilbert, 1995; Mangan \& Reips, 2007).

Ethical considerations in Web-based research are the same as those for other research forms. Consent to participate may be defined as and verified by submission of an online survey. The risk of psychological harm in online surveys has been deemed to be no greater than that of offline surveys (Kraut et al., 2004) if initial instructions include a clear statement respecting the participant's freedom to withdraw from the study at any time. For studies involving sensitive subjects, information concerning referrals for counseling or support may be provided.

\section{Objectives and Hypotheses}

Based on the literature reviewed here, it appears that preabortion counseling for women may be limited, whereas for men, it is nonexistent. In addition, men and women may be arriving at abortion decisions that are made without adequate communication and candor between them thus resulting in decisions that are less than satisfactory to one or both parties. Consequent to both the crisis of pregnancy resolution and insufficient communication, relationships may be strained (Rue et al., 2004; Speckhard \& Rue, 1993) and psychological stress increased (Bagarozzi, 1994; Coleman \& Nelson, 1998; Fergusson et al., 2006).

Both inadequate preabortion counseling and the incongruence of partner abortion decision making may therefore predict postabortion relationship difficulties and/or psychological trauma. Given that some studies on women have found factors such as prior mental health (Major et al., 2000), religious beliefs (Adler et al., 1990; Major, Richards, Cooper, Cozzarelli, \& Zubek, 1998), opinions or attitudes about abortion (Soderberg et al., 1998; Zolese \& Blacker, 1992), number of abortions (Rue et al., 2004), and various sociodemographic characteristics (Zavodny, 2001) are likely to influence the decision to abort and/or postabortion adjustment, these factors were used as control variables in this 
study. In addition, history of physical or sexual abuse during childhood or adulthood may be a confounding variable in terms of postabortion mental health given the evidence that such abuse may contribute to emotional problems (Fergusson, Horwood, \& Lynskey, 1996; Schilling, Aseltine, \& Gore, 2007). Therefore, controls were also implemented for various forms of childhood and adulthood victimization.

The primary objective of this study was to investigate the extent to which perceived inadequacy of preabortion counseling and partner incongruence in abortion decision making predicted postabortion relationship problems and psychological stress. The following hypotheses were tested:

Hypothesis 1: Men and women who do not perceive preabortion counseling as having been adequate will be at significantly greater risk for abortionrelated anger, relationship problems, and sexual problems after controlling for sociodemographic and personal history variables.

Hypothesis 2: Men and women who do not perceive preabortion counseling as adequate will report significantly higher abortion-related stress as evidenced by symptoms of intrusion, avoidance, and hyperarousal, and they will be at significantly greater risk of meeting the Diagnostic and Statistical Manual of Mental Disorders, fourth edition (DSM-IV) diagnostic criteria for PTSD after controlling for sociodemographic and personal history variables.

Hypothesis 3: Men and women who were not in agreement with their partners regarding the decision to abort will be at significantly greater risk for abortion-related anger, relationship problems, and sexual problems after controlling for sociodemographic and personal history variables.

Hypothesis 4: Men and women who were not in agreement with their partners regarding the decision to abort will report significantly higher abortion-related stress as evidenced by symptoms of intrusion, avoidance, and hyperarousal, and they will be at significantly greater risk of meeting the $D S M-I V$ diagnostic criteria for PTSD after controlling for sociodemographic and personal history variables.

\section{Method}

\section{Procedure}

Surveys were posted at www.abortionresearch.net from April, 2005 through August, 2008. The surveys consisted of questions concerning sociodemographics, meaningfulness of religious affiliation, abortion history, reasons for abortion, perceived adequacy of preabortion counseling, agreement in abortion decision making, opinion regarding abortion at time of procedure, relationship status with partner postabortion, mental health history, abuse history, trauma symptoms related to abortion, abortion-related anger, relationship problems, sexual problems, and general stress attributed to abortion. The introduction to the survey clarified that submission of the survey would qualify as consent to participate and that respondents could withdraw from participation at any time. Links were provided for those respondents who desired support or counseling. Participants were recruited through e-mail requests to crisis pregnancy centers across the United States and to a few other organizations that offer postabortion counseling. Potential participants could also find the survey via search engines using phrases such as "men and abortion," "women and abortion," or "abortion research."

\section{Sample}

Surveys were completed by 374 women and 198 men. U.S. citizens comprised $81 \%$ of the female sample and $78 \%$ of the male sample. Citizens from England (6.5\% male and 4\% female surveys), Canada (4.5\% male and $6.4 \%$ female surveys), and Australia (2.5\% male and 2.7\% female surveys) contributed the next largest number of surveys. Respondents also identified the following as country of citizenship: France, Ireland, Norway, Romania, Czechoslovakia, Germany, Sweden, New Zealand, South Africa, Kenya, Mexico, Nicaragua, Brazil, Nepal, and South Korea. The average age of both male and female respondents was 38 years $(S D=12.8$ for males and 11.1 for females $)$. Religious affiliation of women was as follows: $81.6 \%$ Christian, $0.3 \%$ Jewish, 9.5\% Other, and $8.6 \%$ None. Religious affiliation of males was $82 \%$ Christian, 0.5\% Jewish, 0.5\% Islam, 7.2\% Other, and $9.8 \%$ None. Females reported an average of 15 years $(S D=11.8)$ had elapsed since abortion and males reported a mean of 14.7 years $(S D=12)$ had passed since abortion occurred. Approximately half of the respondents endorsed liberal views prior to abortion with $21 \%$ of males and $24 \%$ of females agreeing that abortion "should be legal for any reason at any time during pregnancy" and $27 \%$ of males and $36 \%$ of females agreeing that abortion "should be legal for any reason during the first trimester of pregnancy." Additional demographic information can be found in Table 1.

\section{Measures}

Perceived adequacy of preabortion counseling was assessed via a single item question, "Do you think the counseling you received at the abortion clinic was adequate?" to which respondents indicated "yes" or "no." Agreement regarding abortion decision making was determined by respondents' endorsement of agreement or disagreement with their partners about the decision to abort.

Relationship quality was assessed with single item variables indicating the presence or absence of abortionrelated relationship problems, abortion-related anger, and 
Table I. Descriptive Statistics for Primary Study Variables and Control Variables

\begin{tabular}{|c|c|c|}
\hline \multirow[b]{2}{*}{ Variables } & \multicolumn{2}{|c|}{ Percentage } \\
\hline & Women & Men \\
\hline \multicolumn{3}{|l|}{ Independent variables } \\
\hline \multicolumn{3}{|l|}{ Inadequate preabortion counseling } \\
\hline Endorsed & 85.8 & 86.6 \\
\hline Not endorsed & 14.2 & 13.4 \\
\hline \multicolumn{3}{|l|}{$\begin{array}{l}\text { Respondent and partner did not agree } \\
\text { on abortion decision }\end{array}$} \\
\hline Endorsed & 50.7 & 52.9 \\
\hline Not endorsed & 49.3 & 47.1 \\
\hline \multicolumn{3}{|l|}{ Control variables } \\
\hline \multicolumn{3}{|l|}{ Race } \\
\hline White & 85.4 & 85.2 \\
\hline Black & 3.0 & 7.7 \\
\hline Hispanic & 5.7 & 2.0 \\
\hline Asian & 0.5 & 1.0 \\
\hline Other & 5.4 & 4.1 \\
\hline \multicolumn{3}{|l|}{ Education } \\
\hline Less than 12 years & 2.7 & 4.1 \\
\hline High school diploma & 21.4 & 19.4 \\
\hline Technical/associates degree & 29.2 & 26.5 \\
\hline Bachelor degree & 28.7 & 29.6 \\
\hline Graduate degree & 18.0 & 20.4 \\
\hline \multicolumn{3}{|l|}{ Employment } \\
\hline Full-time & 49.0 & 74.5 \\
\hline Part-time & 24.3 & 10.7 \\
\hline Unemployed & 26.7 & 14.8 \\
\hline \multicolumn{3}{|l|}{ Marital status } \\
\hline Married & 48.0 & 37.8 \\
\hline Remarried & 10.5 & 6.1 \\
\hline Single (never married) & 26.4 & 39.3 \\
\hline Single (divorced) & 12.1 & 14.8 \\
\hline Separated & 2.2 & 2.0 \\
\hline \multicolumn{3}{|l|}{ Number of children } \\
\hline None & 42.0 & 55.1 \\
\hline One & 12.8 & II.I \\
\hline Two & 23.0 & 17.7 \\
\hline Three & 13.9 & 9.6 \\
\hline Four or more & 8.2 & 6.5 \\
\hline \multicolumn{3}{|l|}{ Number of abortions } \\
\hline One & 73.4 & 81.8 \\
\hline Two or more & 26.6 & 18.2 \\
\hline \multicolumn{3}{|l|}{ Meaningfulness of respondent's religion } \\
\hline Not at all & 8.2 & 10.3 \\
\hline Not very & 4.4 & 8.8 \\
\hline Somewhat & 10.7 & 17.5 \\
\hline Important & 12.1 & 14.4 \\
\hline Very important & 64.6 & 49.0 \\
\hline \multicolumn{3}{|l|}{ Abortion position at time of procedure } \\
\hline $\begin{array}{l}\text { Legal for any reason at anytime } \\
\text { in pregnancy }\end{array}$ & 24.2 & 20.9 \\
\hline Legal for any reason in first trimester & 36.3 & 27.0 \\
\hline $\begin{array}{l}\text { Legal only in rape, incest, } \\
\text { genetic disorders, and to } \\
\text { preserve health of mothers }\end{array}$ & 9.2 & 11.7 \\
\hline $\begin{array}{l}\text { Legal only in rape, incest, and to } \\
\text { preserve mother's health }\end{array}$ & 6.7 & 16.6 \\
\hline
\end{tabular}

Table I. (continued)

\begin{tabular}{|c|c|c|}
\hline \multirow[b]{2}{*}{ Variables } & \multicolumn{2}{|c|}{ Percentage } \\
\hline & Women & Men \\
\hline $\begin{array}{l}\text { Legal only if mother's } \\
\text { health is threatened }\end{array}$ & 7.6 & 8.6 \\
\hline Never legal & 15.9 & 15.3 \\
\hline \multicolumn{3}{|l|}{$\begin{array}{l}\text { Mental health counseling } \\
\text { prior to abortion }\end{array}$} \\
\hline Yes & 27.5 & 13.5 \\
\hline No & 72.5 & 86.5 \\
\hline \multicolumn{3}{|c|}{$\begin{array}{l}\text { Hospitalized for emotional } \\
\text { reasons prior to abortion }\end{array}$} \\
\hline Yes & 3.8 & 4.2 \\
\hline No & 96.2 & 95.8 \\
\hline \multicolumn{3}{|l|}{$\begin{array}{l}\text { Told needed counseling } \\
\text { before abortion but did }\end{array}$} \\
\hline Yes & 22.7 & 20.2 \\
\hline No & 77.3 & 79.8 \\
\hline \multicolumn{3}{|c|}{$\begin{array}{l}\text { Felt needed counseling before } \\
\text { abortion but did not go }\end{array}$} \\
\hline Yes & 23.6 & 17.2 \\
\hline No & 76.4 & 82.8 \\
\hline \multicolumn{3}{|l|}{ Victim of child abuse } \\
\hline Yes & 24.1 & 15.6 \\
\hline No & 75.9 & 84.4 \\
\hline \multicolumn{3}{|l|}{ Victim of child neglect } \\
\hline Yes & 18.9 & 17.8 \\
\hline No & 81.1 & 82.2 \\
\hline \multicolumn{3}{|c|}{$\begin{array}{l}\text { Victim of sexual abuse in } \\
\text { childhood or adolescence }\end{array}$} \\
\hline Yes & 36.7 & 19.4 \\
\hline No & 63.3 & 80.6 \\
\hline \multicolumn{3}{|l|}{$\begin{array}{l}\text { Victim of physical abuse } \\
\text { during adulthood }\end{array}$} \\
\hline Yes & 26.3 & 6.5 \\
\hline No & 73.7 & 93.5 \\
\hline \multicolumn{3}{|l|}{$\begin{array}{l}\text { Victim of sexual abuse } \\
\text { during adulthood }\end{array}$} \\
\hline Yes & 32.5 & 5.5 \\
\hline No & 67.5 & 94.5 \\
\hline \multicolumn{3}{|l|}{ Dependent variables } \\
\hline \multicolumn{3}{|l|}{ Abortion-related anger } \\
\hline Yes & 86.6 & 79.8 \\
\hline No & 13.4 & 30.2 \\
\hline \multicolumn{3}{|c|}{ Abortion-related relationship problems } \\
\hline Yes & 82.6 & 81.8 \\
\hline No & 17.4 & 18.2 \\
\hline \multicolumn{3}{|c|}{ Abortion-related sexual problems } \\
\hline Yes & 69.5 & 55.6 \\
\hline No & 30.5 & 44.4 \\
\hline \multicolumn{3}{|c|}{ Met DSM-IV criteria for intrusion } \\
\hline Yes & 83.5 & 77.6 \\
\hline No & 16.5 & 22.4 \\
\hline \multicolumn{3}{|c|}{ Met DSM-IV criteria for avoidance } \\
\hline Yes & 74.1 & 59.4 \\
\hline No & 25.9 & 40.6 \\
\hline \multicolumn{3}{|c|}{ Met DSM-IV criteria for hyperarousal } \\
\hline Yes & 61.6 & 54.2 \\
\hline No & 38.4 & 45.8 \\
\hline
\end{tabular}


Table I. (continued)

\begin{tabular}{lrr}
\hline & \multicolumn{2}{c}{ Percentage } \\
\cline { 2 - 3 } Variables & Women & Men \\
\hline Met DSM-IV diagnostic & & \\
criteria for PTSD & & \\
Yes & 54.9 & 43.4 \\
No & 45.1 & 56.6 \\
Stress associated with the abortion & & \\
(0 = no stress; 4 = moderate stress; 7 & & \\
= high stress; 10 = overwhelming stress) & & \\
0-2 & 5.7 & 6.2 \\
3-4 & 7.9 & 14.4 \\
5-6 & 8.2 & 8.3 \\
7-8 & 22.1 & 29.9 \\
9-10 & 56.3 & 41.2 \\
\hline
\end{tabular}

Note: DSM-IV = Diagnostic and Statistical Manual of Mental Disorders, fourth edition; PTSD = posttraumatic stress disorder.

abortion-related sexual problems. These items had dichotomous (yes/no) responses.

Psychological stress was assessed using the PTSD Checklist-Civilian Version (PCL-C). The entire PCL-C was contained within the online survey. The PCL is composed of 17 items that measure the severity of PTSD symptoms. The PCL yields a total score of 17 to 85 and assesses three symptom clusters: arousal, avoidance of, and re-experiencing of the traumatic event. The response format of the PCL is a 5-point Likert-type scale with higher scores indicative of greater traumatic stress. The diagnosis of PTSD was determined using $D S M-I V$ criteria: (a) one or more endorsements of re-experience symptoms; (b) three or more endorsements of avoidance symptoms; and (c) two or more endorsements of hyperarousal symptoms not present prior to the abortion. Reliability and validity of the PCL have been established (Weathers, Litz, Herman, Huska, \& Keane, 1993). With the current sample, internal consistency reliability estimates for the full scale and for the arousal, avoidance, and re-experiencing subscales were equal to $.89, .77, .78, .80$, and $.92, .82, .80, .82$ using the women's and men's data, respectively.

\section{Results}

Table 1 provides frequency data for the independent variables, sociodemographic and personal history control variables, and dependent variables separately for men and women. To test the first and third hypotheses, which predicted that perceptions of inadequate preabortion counseling and disagreement with one's partner regarding the decision to abort would be associated with increased risk for abortion-related anger, relationship, and sexual problems after employing various controls, three sets of logistic regression analyses were conducted separately for males and females in the sample. In the first set, perceptions of counseling inadequacy and partner disagreement operated as the independent variables with abortion-related anger problems functioning as the dependent variable. A similar logistic regression analysis was then conducted incorporating the control variables listed in Table 1. In the second set of two logistic regression analyses, the analyses were structured similarly to the first set except relationship problems functioned as the dependent variable. Finally, in the third set of logistic regressions employing a similar structure to the preceding analyses, sexual problems operated as the dependent variable.

The results of these tests are provided in Table 2 for the female respondents and in Table 3 for the male respondents. As indicated by the data presented in Table 2, prior to inclusion of the control variables, both independent variables (disagreement regarding the abortion decision and perceptions of preabortion counseling as inadequate) were significant predictors of abortion-related anger, relationship, and sexual problems. However, once the controls were entered into the analyses, only the inadequate preabortion counseling variable significantly predicted postabortion-related anger, relationship, and sexual problems in the women sampled. More specifically, the inadequate counseling variable was associated with a $592 \%$, $831 \%$, and $340 \%$ increased risk for anger, relationship, and sexual problems, respectively, among the females.

A different pattern of results emerged with the male data. As indicated in Table 3, both independent variables were significant predictors of postabortion-related anger, relationship, and sexual problems after statistically controlling for the wide range of sociodemographic and personal situational variables. Inadequate counseling was specifically associated with a $1,797 \%$ increased risk of postabortion anger, a 1,421\% increased risk of postabortion relationship problems, and a $407 \%$ increased risk of postabortion-related sexual problems. In addition, disagreement with one's partner regarding the abortion decision was associated with a 4,248\%, 469\%, and a $331 \%$ increased risk of postabortion-related anger, relationship problems, and sexual problems, respectively.

To test the first part of the second and fourth hypotheses, two sets (one for males and one for females) of analyses of variance were conducted. In each test, the independent variables of partner disagreement on the decision and preabortion counseling inadequacy served as the independent variables with scores on the single item measure of abortion-related stress serving as the dependent variable. Higher scores on the stress measure are indicative of greater stress. One analysis in each set incorporated controls and one did not. Using the female data, without controls employed, the main effect for counseling inadequacy was significant, $F(1,334)=71.92$, $p<.0001$, as was the main effect for partner disagreement, $F(1,334)=71.92, p<.0001$, and the interaction was significant as well, $F(1,334)=20.58, p<.0001$. Then, with the controls instituted, the results were similar-counseling inadequacy: $F(1,218)=36.31, p<.0001$; partner disagreement: $F(1,218)=12.23, p<.0001$; interaction: $F(1,334)=$ $5.45, p<.0001$. Means were as follows - no agreement, counseling inadequate: $8.80(S E=.21)$; no agreement, 
Table 2. Results of Logistic Regression Analyses With Relationship-Based Dependent Variables for Females

\begin{tabular}{|c|c|c|c|c|c|c|}
\hline Dependent Variable & Independent Variable & $B$ & SE & $\operatorname{Exp}(B)$ & $95 \% \mathrm{Cl}$ for $\operatorname{Exp}(B)$ & Significance \\
\hline \multirow[t]{2}{*}{$\begin{array}{l}\text { Abortion- } \\
\text { related anger }\end{array}$} & $\begin{array}{l}\text { Respondent and partner not in } \\
\text { agreement on abortion }\end{array}$ & 1.45 & 0.42 & 4.25 & $1.85-9.74$ & .001 \\
\hline & Inadequate preabortion counseling & 2.69 & 0.38 & 14.68 & $6.95-30.98$ & .0001 \\
\hline \multirow[t]{2}{*}{ Abortion-related anger ${ }^{\mathrm{a}}$} & $\begin{array}{l}\text { Respondent and partner } \\
\text { not in agreement on abortion }\end{array}$ & 0.56 & 0.55 & 1.75 & $0.60-5.13$ & .309 \\
\hline & Inadequate preabortion counseling & 1.93 & 0.64 & 6.92 & $1.97-24.34$ & .003 \\
\hline \multirow[t]{2}{*}{$\begin{array}{l}\text { Abortion-related } \\
\text { relationship problems }\end{array}$} & $\begin{array}{l}\text { Respondent and partner not } \\
\text { in agreement on abortion }\end{array}$ & 1.08 & 0.35 & 2.94 & $1.474-5.89$ & .002 \\
\hline & Inadequate preabortion counseling & 2.54 & 0.36 & 12.69 & $6.26-25.66$ & .0001 \\
\hline \multirow[t]{2}{*}{$\begin{array}{l}\text { Abortion-related } \\
\text { relationship problems }{ }^{\mathrm{a}}\end{array}$} & $\begin{array}{l}\text { Respondent and partner } \\
\text { not in agreement on abortion }\end{array}$ & 0.73 & 0.48 & 2.08 & $0.813-5.33$ & .126 \\
\hline & Inadequate preabortion counseling & 2.23 & 0.61 & 9.31 & $2.805-30.91$ & .0001 \\
\hline \multirow[t]{2}{*}{$\begin{array}{l}\text { Abortion-related } \\
\text { sexual problems }\end{array}$} & $\begin{array}{l}\text { Respondent and partner } \\
\text { not in agreement on abortion }\end{array}$ & 0.52 & 0.25 & 1.68 & $1.03-2.76$ & .039 \\
\hline & Inadequate preabortion counseling & 1.66 & 0.33 & 5.26 & $2.74-10.10$ & .0001 \\
\hline \multirow[t]{2}{*}{$\begin{array}{l}\text { Abortion-related } \\
\text { sexual problems }\end{array}$} & $\begin{array}{l}\text { Respondent and partner not } \\
\text { in agreement on abortion }\end{array}$ & 0.44 & 0.34 & 1.55 & $0.80-3.03$ & .196 \\
\hline & Inadequate preabortion counseling & 1.48 & 0.53 & 4.40 & $1.56-12.38$ & .005 \\
\hline
\end{tabular}

a. Controlled for race, education, marital status, employment, number of children, number of abortions, the meaningfulness of the respondent's religion, the respondent's view on the legality of abortion prior to the abortion, mental health counseling before the abortion, hospitalized for emotional reasons before the abortion, told he or she needed counseling before the abortion, respondent felt he or she needed counseling before the abortion, victim of child abuse, child neglect, sexual abuse in childhood or adolescence, physical abuse in adulthood, or sexual abuse in adulthood.

Table 3. Results of Logistic Regression Analyses With Relationship-Based Dependent Variables for Males

\begin{tabular}{|c|c|c|c|c|c|c|}
\hline Dependent Variable & Independent Variable & B & SE & $\operatorname{Exp}(B)$ & $95 \% \mathrm{Cl}$ for $\operatorname{Exp}(B)$ & Significance \\
\hline \multirow[t]{2}{*}{ Abortion-related anger } & $\begin{array}{l}\text { Respondent and partner } \\
\text { not in agreement on abortion }\end{array}$ & 2.78 & 0.64 & 16.10 & $4.58-56.62$ & .0001 \\
\hline & Inadequate preabortion counseling & 1.46 & 0.56 & 4.30 & $1.42-13.01$ & .010 \\
\hline \multirow[t]{2}{*}{ Abortion-related anger ${ }^{\mathrm{a}}$} & $\begin{array}{l}\text { Respondent and partner not } \\
\text { in agreement on abortion }\end{array}$ & 3.77 & 1.08 & 43.48 & $5.24-360.43$ & .0001 \\
\hline & Inadequate preabortion counseling & 2.94 & 1.01 & 18.97 & $2.63-136.69$ & .003 \\
\hline \multirow[t]{2}{*}{$\begin{array}{l}\text { Abortion-related } \\
\text { relationship problems }\end{array}$} & $\begin{array}{l}\text { Respondent and partner } \\
\text { not in agreement on abortion }\end{array}$ & 1.55 & 0.56 & 4.70 & I.57-| 4.05 & .006 \\
\hline & Inadequate preabortion counseling & 2.67 & 0.60 & 14.47 & $4.43-47.29$ & .0001 \\
\hline \multirow[t]{2}{*}{$\begin{array}{l}\text { Abortion-related } \\
\text { relationship problems }{ }^{\mathrm{a}}\end{array}$} & $\begin{array}{l}\text { Respondent and partner } \\
\text { not in agreement on abortion }\end{array}$ & 1.74 & 0.81 & 5.69 & I. $15-28.02$ & .033 \\
\hline & Inadequate preabortion counseling & 2.72 & 0.91 & $|5.2|$ & $2.57-89.95$ & .003 \\
\hline \multirow[t]{2}{*}{$\begin{array}{l}\text { Abortion-related } \\
\text { sexual problems }\end{array}$} & $\begin{array}{l}\text { Respondent and partner } \\
\text { not in agreement on abortion }\end{array}$ & 0.89 & 0.34 & 2.43 & $1.23-4.78$ & .010 \\
\hline & Inadequate preabortion counseling & 1.37 & 0.61 & 3.95 & $1.20-12.97$ & .023 \\
\hline \multirow[t]{2}{*}{$\begin{array}{l}\text { Abortion-related } \\
\text { sexual problems }\end{array}$} & $\begin{array}{l}\text { Respondent and partner not } \\
\text { in agreement on abortion }\end{array}$ & 1.46 & 0.51 & 4.31 & $1.58-11.74$ & .004 \\
\hline & Inadequate preabortion counseling & 1.62 & 0.83 & 5.07 & $1.00-25.77$ & .050 \\
\hline
\end{tabular}

a. Controlled for race, education, marital status, employment, number of children, number of abortions, the meaningfulness of the respondent's religion, the respondent's view on the legality of abortion prior to the abortion, mental health counseling before the abortion, hospitalized for emotional reasons before the abortion, told he or she needed counseling before the abortion, respondent felt he or she needed counseling before the abortion, victim of child abuse, child neglect, sexual abuse in childhood or adolescence, physical abuse in adulthood, or sexual abuse in adulthood.

counseling adequate: $8.26(S E=.23)$; agreement, counseling inadequate: $6.78(S E=.77)$; agreement, counseling adequate: $3.96(S E=.56)$.

Using the male data, without controls employed, only the main effect for partner disagreement was significant, $F(1$,
$152)=10.99, p<.001$. Then, with the controls instituted, partner disagreement remained significant, $F(1,95)=8.24$, $p=.005$, and the interaction effect was likewise significant, $F(1,95)=4.00, p=.048$. Adjusted means were as followsno agreement, counseling inadequate: $7.81(S E=.36)$; no 
agreement, counseling adequate: $8.28(S E=1.77)$; agreement, counseling inadequate: $6.94(S E=.38)$; agreement, counseling adequate: $3.49(S E=.73)$.

To test the second part of the second and fourth hypotheses, which predicted that inadequate preabortion counseling and partner disagreement on the abortion decision would be associated with higher risk for experiencing intrusion, avoidance, hyperarousal, and with meeting diagnostic criteria for PTSD after employing controls, four sets of logistic regression analyses were conducted separately for males and females in the sample. The dependent variable in each of the four sets of two analyses was different (intrusion criteria, avoidance criteria, hyperarousal criteria, and general PTSD criteria met) and as in the previous set of logistic regressions performed to test the first and third hypotheses, there were separate tests conducted with and without the controls. Table 4 provides these results for women, and Table 5 provides these results for men.

With the female data, both independent variables were associated with increased risk for meeting the DSM-IV criteria for intrusion $(202 \%$ and $2,383 \%$ for the partner disagreement and inadequate counseling variables, respectively) and full PTSD diagnostic criteria after the controls were applied (89\% and 283\% for the partner disagreement and inadequate counseling variables, respectively.) However, only the inadequate counseling variable was a significant predictor after the controls were included on the avoidance subscale (559\% increased risk) and on the hyperarousal subscale ( $425 \%$ increased risk). Using the male data, both independent variables were associated with increased risk of meeting the $D S M-I V$ criteria on the intrusion subscale (925\% and 1,737\% for the partner disagreement and inadequate counseling variables, respectively). However, only the inadequate counseling variable was associated with increased risk for meeting the $D S M-I V$ criteria for the avoidance subscale $(1,005 \%)$ after controls were applied. Only partner disagreement over the abortion decision increased risk for experiencing hyperarousal symptoms $(384 \%)$ and for meeting the full diagnostic criteria for PTSD (210\%).

\section{Discussion}

The purpose of this study was to explore associations between two independent variables (perceptions of preabortion counseling adequacy and partner abortion decision congruence) and two sets of dependent variables (postabortion relationship problems and psychological stress). Perceptions of inadequate preabortion counseling significantly predicted all the dependent relationship variables for both men and women with utilization of control variables. Although other research has found abortion in itself to be associated with abortion-related anger (Kero, Hogberg, \& Lalos, 2004; Naziri, 2007), relationship difficulties (Barnett, Freudenberg, \& Wille, 1992; Lauzon et al., 2000; Rue et al., 2004), and sexual dysfunction (Bradshaw \& Slade, 2003; Rue et al., 2004), no studies had previously investigated the association between preabortion counseling and postabortion relationship challenges. The inclusion of participants' perceptions of counseling adequacy is therefore an important contribution of the current study.

For women, perceived inadequate counseling also predicted all trauma subscale scores (i.e., intrusion, avoidance, hyperarousal) and predicted meeting diagnostic criteria for PTSD. For men, only intrusion and avoidance scores were predicted by perceptions of inadequate counseling. Similarly, Peters, Issakidis, Slade, and Andrews (2006) observed that whereas women were significantly more likely to report arousal symptoms, men were significantly more likely to report avoidance symptoms particularly the symptom of detachment. Both biological (Bryant \& Harvey, 2003) and sociocultural (Gavranidou \& Rosner, 2003) explanations have been proposed to explain these observed differences between men's and women's endorsement of specific PTSD symptoms. From a biological perspective, males and females may have innate predispositions that differentiate their responses to trauma. Alternatively, culturally prescribed gender roles may influence which trauma symptoms men and women are likely to endorse depending on whether symptoms are perceived as being gender appropriate.

Sex differences in the association between perceived counseling inadequacy and meeting full diagnostic criteria for PTSD may be related to women's direct participation in the abortion procedure, which could predispose them to greater trauma and an increased likelihood of developing PTSD regardless of the quality of counseling. Nonetheless, a large majority of both women and men $(85.8 \%$ and $86.6 \%$, respectively) in this study indicated that they did not perceive preabortion counseling to be adequate. Because abortion is the legal right of females in the United States and continues to be viewed as an exclusively women's issue, there are no requirements or incentives to offer counseling to male partners. If men receive any counseling at all, it is likely to occur informally if and when they accompany their partners for preabortion clinic visits.

When unplanned pregnancy is experienced as a crisis situation for one or both partners, the individuals tend to use more primitive coping skills and to be psychologically vulnerable as they struggle to solve the problem and regain equilibrium (Caplan, 1961). The emotional strain of the crisis and the lack of effectiveness of one's usual coping mechanisms may result in anxiety and an inability to function (Caplan, 1961). Thus, men and women facing a crisis pregnancy may need considerably more counseling than is currently being offered.

With control variables applied, incongruence of abortion decision significantly predicted trauma symptoms of intrusion and meeting diagnostic criteria for PTSD for both men and women. Contrary to the findings concerning counseling adequacy, disagreement about the abortion decision predicted 
Table 4. Results of Logistic Regression Analyses With Posttraumatic Stress Disorder (PTSD) Subscales and Total Scale Criteria Met for Females

\begin{tabular}{|c|c|c|c|c|c|c|}
\hline Dependent Variable & Independent Variable & B & SE & $\operatorname{Exp}(B)$ & $95 \% \mathrm{Cl}$ for $\operatorname{Exp}(B)$ & Significance \\
\hline \multirow[t]{2}{*}{ Intrusion subscale } & $\begin{array}{l}\text { Respondent and partner } \\
\text { not in agreement on abortion }\end{array}$ & 1.00 & 0.37 & 2.73 & $1.33-5.59$ & .006 \\
\hline & Inadequate preabortion counseling & 2.88 & 0.38 & 17.74 & $8.5 I-37.00$ & .0001 \\
\hline \multirow[t]{2}{*}{ Intrusion subscale ${ }^{\mathrm{a}}$} & $\begin{array}{l}\text { Respondent and partner } \\
\text { not in agreement on abortion }\end{array}$ & I.II & 0.51 & 3.02 & $||.|-8.2|$ & .030 \\
\hline & Inadequate preabortion counseling & 3.21 & 0.74 & 24.83 & $5.80-106.37$ & .0001 \\
\hline \multirow[t]{2}{*}{ Avoidance subscale } & $\begin{array}{l}\text { Respondent and partner } \\
\text { not in agreement on abortion }\end{array}$ & 0.86 & 0.29 & 2.35 & $1.33-4.17$ & .003 \\
\hline & Inadequate preabortion counseling & 2.54 & 0.39 & 12.72 & $5.98-27.04$ & .0001 \\
\hline \multirow[t]{2}{*}{ Avoidance subscale ${ }^{a}$} & $\begin{array}{l}\text { Respondent and partner } \\
\text { not in agreement on abortion }\end{array}$ & 0.67 & 0.39 & 1.95 & $0.92-4.15$ & .083 \\
\hline & Inadequate preabortion counseling & 1.89 & 0.57 & 6.59 & $2.16-20.11$ & .001 \\
\hline \multirow[t]{2}{*}{ Hyperarousal subscale } & $\begin{array}{l}\text { Respondent and partner } \\
\text { not in agreement on abortion }\end{array}$ & 0.38 & 0.24 & 1.47 & $0.9 \mid-2.35$ & .114 \\
\hline & Inadequate preabortion counseling & 1.66 & 0.35 & 5.25 & $2.63-10.47$ & .0001 \\
\hline \multirow[t]{2}{*}{ Hyperarousal subscale ${ }^{a}$} & $\begin{array}{l}\text { Respondent and partner } \\
\text { not in agreement on abortion }\end{array}$ & 0.31 & 0.31 & 1.36 & $0.74-2.52$ & .325 \\
\hline & Inadequate preabortion counseling & 1.48 & 0.54 & 4.39 & $1.53-12.6 \mid$ & .006 \\
\hline \multirow[t]{2}{*}{ PTSD total scale } & $\begin{array}{l}\text { Respondent and partner } \\
\text { not in agreement on abortion }\end{array}$ & 0.64 & 0.24 & 1.89 & I.17-3.05 & .009 \\
\hline & Inadequate preabortion counseling & 1.80 & 0.41 & 6.06 & $2.69-13.66$ & .0001 \\
\hline \multirow[t]{2}{*}{ PTSD total scale ${ }^{a}$} & $\begin{array}{l}\text { Respondent and partner } \\
\text { not in agreement on abortion }\end{array}$ & 0.64 & 0.32 & 1.89 & $1.01-3.55$ & .046 \\
\hline & Inadequate pre-abortion counseling & 1.34 & 0.57 & 3.83 & $1.25-11.74$ & .019 \\
\hline
\end{tabular}

a. Controlled for race, education, marital status, employment, number of children, number of abortions, the meaningfulness of the respondent's religion, the respondent's view on the legality of abortion prior to the abortion, mental health counseling before the abortion, hospitalized for emotional reasons before the abortion, told he or she needed counseling before the abortion, respondent felt he or she needed counseling before the abortion, victim of child abuse, child neglect, sexual abuse in childhood or adolescence, physical abuse in adulthood, or sexual abuse in adulthood.

hyperarousal in men but not in women. Furthermore, decision incongruence predicted abortion-related anger, relationship problems, and sexual difficulties for men only. The inherent inequality of abortion decisions may explain these differential associations.

Numerous studies (Bracken, Hachamovitch, \& Grossman, 1974; Major, Zubek, Cooper, Cozzarelli, \& Richards, 1997; Moseley, Follingstad, Harley, \& Heckel, 1981; Payne et al., 1976) have identified conflict with one's partner and lack of partner support for abortion as predictors of women's postabortion distress. In contrast, very few studies, with the exception of work by Shostak and McLouth (1984) and Naziri (2007), have examined the male's reaction to an abortion that occurs against his wishes. Our findings suggest that disagreement about abortion decisions may be a more robust predictor of traumatic stress among men compared with women.

A notable feature of this study is that it is the first to explore the association between preabortion counseling and postabortion relationship problems and postabortion psychological stress. Employment of numerous control variables, including prior mental health, which has been found to be a determinant of both postabortion adjustment (Major et al., 2000) and PTSD (Brewin, Andrews, \& Valentine, 2000), is a major strength of this investigation. Also included as control variables were other known risk factors for the development of PTSD, including history of childhood sexual abuse (Astin, Lawrence, \& Foy, 1993), childhood physical abuse (Bremner, Southwick, Johnson, Yehuda, \& Charney, 1993; O'Keefe, 1998), physical abuse during adulthood (Breslau, Davis, Andreski, \& Peterson, 1991), and sexual abuse during adulthood (Kessler, Sonnega, Bromet, Hughes, \& Nelson, 1995).

The use of the Internet is another asset of this study as it enabled acquisition of an international sample and offered anonymity for those who may have been hesitant to participate in research concerning such a sensitive topic. The anonymity afforded by an online survey may augment respondents' perceptions of safety and enhance honest disclosure. Finally, the inclusion of men as well as women is an essential strength of this investigation as the research pertaining to men's responses to abortion is severely inadequate.

A limitation of this study is the fact that the sample was self-selected. Although self-selection may bring some benefits such as a high level of motivation and a genuine desire to contribute to science, self-selected samples limit generalizability of findings. Moreover, the high rate of PTSD among respondents ( $54.9 \%$ of women, $43.4 \%$ of men) is indicative of a traumatized sample. By comparison, prevalence of PTSD among women with a history of assault has been 
Table 5. Results of Logistic Regression Analyses With Posttraumatic Stress Disorder (PTSD) Subscales and Total Scale Criteria Met for Males

\begin{tabular}{|c|c|c|c|c|c|c|}
\hline Dependent Variable & Independent Variable & $B$ & SE & $\operatorname{Exp}(B)$ & $95 \% \mathrm{Cl}$ for $\operatorname{Exp}(B)$ & Significance \\
\hline \multirow[t]{2}{*}{ Intrusion subscale } & $\begin{array}{l}\text { Respondent and partner } \\
\text { not in agreement on abortion }\end{array}$ & 2.19 & 0.53 & 8.94 & $3.16-25.29$ & .0001 \\
\hline & Inadequate preabortion counseling & 1.70 & 0.57 & 5.48 & $1.78-16.89$ & .003 \\
\hline \multirow[t]{2}{*}{ Intrusion subscale ${ }^{a}$} & $\begin{array}{l}\text { Respondent and partner } \\
\text { not in agreement on abortion }\end{array}$ & 2.33 & 0.73 & 10.25 & $2.47-42.49$ & .001 \\
\hline & Inadequate preabortion counseling & 2.91 & 0.97 & 18.37 & $2.77-121.83$ & .003 \\
\hline \multirow[t]{2}{*}{ Avoidance subscale } & $\begin{array}{l}\text { Respondent and partner } \\
\text { not in agreement on abortion }\end{array}$ & 1.02 & 0.36 & 2.76 & $1.36-5.62$ & .005 \\
\hline & Inadequate preabortion counseling & 1.91 & 0.67 & 6.76 & $1.82-25.15$ & .004 \\
\hline \multirow[t]{2}{*}{ Avoidance subscale ${ }^{a}$} & $\begin{array}{l}\text { Respondent and partner } \\
\text { not in agreement on abortion }\end{array}$ & 1.01 & 0.52 & 2.75 & $0.99-7.64$ & .052 \\
\hline & Inadequate preabortion counseling & 2.40 & 0.92 & 11.05 & $1.82-67.18$ & .009 \\
\hline \multirow[t]{2}{*}{ Hyperarousal subscale } & $\begin{array}{l}\text { Respondent and partner } \\
\text { not in agreement on abortion }\end{array}$ & 1.27 & 0.35 & 3.57 & I.78-7.14 & .0001 \\
\hline & Inadequate preabortion counseling & 0.63 & 0.58 & 1.87 & $0.60-5.86$ & .279 \\
\hline \multirow[t]{2}{*}{ Hyperarousal subscale ${ }^{a}$} & $\begin{array}{l}\text { Respondent and partner } \\
\text { not in agreement on abortion }\end{array}$ & 1.50 & 0.55 & 4.84 & $1.53-13.13$ & .006 \\
\hline & Inadequate preabortion counseling & 1.28 & 0.89 & 3.60 & $0.64-20.24$ & .148 \\
\hline \multirow[t]{2}{*}{ PTSD total scale } & $\begin{array}{l}\text { Respondent and partner } \\
\text { not in agreement on abortion }\end{array}$ & 1.28 & 0.37 & 3.61 & $\mathrm{I} .75-7.45$ & .001 \\
\hline & Inadequate preabortion counseling & 0.92 & 0.69 & 2.52 & $0.66-9.64$ & .178 \\
\hline \multirow[t]{2}{*}{ PTSD total scale ${ }^{a}$} & $\begin{array}{l}\text { Respondent and partner } \\
\text { not in agreement on abortion }\end{array}$ & 1.13 & 0.53 & 3.10 & I.09-8.85 & .034 \\
\hline & Inadequate preabortion counseling & 0.89 & 0.91 & 2.44 & $0.4|-| 4.57$ & .326 \\
\hline
\end{tabular}

a. Controlled for race, education, marital status, employment, number of children, number of abortions, the meaningfulness of the respondent's religion, the respondent's view on the legality of abortion prior to the abortion, mental health counseling before the abortion, hospitalized for emotional reasons before the abortion, told he or she needed counseling before the abortion, respondent felt he or she needed counseling before the abortion, victim of child abuse, child neglect, sexual abuse in childhood or adolescence, physical abuse in adulthood, or sexual abuse in adulthood.

reported as 21\% (Breslau et al., 1991), among rape survivors, 50\% (Foa, 1997), and among Vietnam veterans with high combat exposure, 31\% (Kulka et al., 1988).

On the other hand, this highly traumatized sample may represent those who drop out of other studies concerning abortion. In a review of 17 such studies (Adler, 1976), the attrition rate was found to be from $13 \%$ to $86 \%$ leading to the conclusion that those women who do not participate in follow-up assessments tend to be the most stressed by abortion. As a result, follow-up studies may underestimate negative responses to abortion. Conceivably, anonymous surveys conducted online may be an effective means to reach these traumatized individuals and to gather information from them concerning their abortion experience.

Abortion is one of the most common surgical procedures among women aged 15 to 44 years (Owings \& Kozak, 1996) and from 1973 through 2005, more than 45 million elective abortions were performed in the United States (Guttmacher Institute, 2008). If even a small percentage of the men and women involved in abortion are severely traumatized, this may represent a large absolute number of individuals who need psychological support. In addition, the increase in suicidal ideation among those with PTSD (Sareen, Houlahan,
Cox, \& Asmundson, 2005) and with subthreshold PTSD symptoms (Marshall et al., 2001) raises serious public health concerns if these individuals are not identified and offered help.

In this study, perceptions of preabortion counseling inadequacy were associated with more negative postabortion outcomes in both women and men. Future research should seek to identify the specific elements of counseling that need to be changed or added to achieve better satisfaction with the content and process. Aspects of preabortion counseling to explore further might include the following: (a) the sufficiency of time allotted for counseling, (b) the nature and quality of training of counselors, (c) the inclusion of men in the preabortion counseling process, (d) whether it is better for men and women to be counseled separately or together, and (e) the comprehensiveness and accuracy of information provided.

Findings reported herein provide preliminary evidence that perceptions of inadequate preabortion counseling and abortion decision incongruence may contribute to relationship challenges between partners and to individual psychological stress. Future research to investigate factors that improve the quality and comprehensiveness of preabortion counseling as well as factors that contribute to decision 
congruence could do much to improve men's and women's postabortion adjustment. In-depth interviews with men and women prior to and after abortion might reveal specific counseling needs that could be incorporated into preabortion counseling protocols. Qualitative studies are needed to delve more deeply into the processes of decision making between women and men facing crisis pregnancies to further our understanding of both intraindividual factors and interpersonal dynamics that may affect the quality and congruence of abortion decisions.

\section{Declaration of Conflicting Interests}

The authors declared no potential conflicts of interests with respect to the authorship and/or publication of this article.

\section{Funding}

The authors received no financial support for the research and/or authorship of this article.

\section{References}

Adler, C. L., \& Zarchin, Y. R. (2002). The "virtual focus group": Using the Internet with pregnant women on home bed rest. Journal of Obstetric, Gynecologic, and Neonatal Nursing, 31, 418-427.

Adler, N. (1976). Sample attrition in studies of psychosocial sequelae of abortion. American Journal of Orthopsychiatry, 45, 446-454.

Adler, N. E., David, H. P., Major, B. N., Roth, S. H., Russo, N. F., \& Wyatt, G. E. (1990). Psychological responses after abortion. Science, 248, 41-44.

American Psychological Association. (2008). Report of the APA task force mental health and abortion. Released August 13. Retrieved August 23, 2009, from http://www.apa.org/releases/ abortion-report.pdf

Astin, M. C., Lawrence, K. J., \& Foy, D. W. (1993). Posttraumatic stress disorder among battered women: Risk and resiliency factors. Violence and Victims, 8, 17-28.

Bagarozzi, D. (1993). Post traumatic stress disorders in women following abortion: Some considerations and implications for marital/couple therapy. International Journal of Family and Marriage, 1, 51-68.

Bagarozzi, D. (1994). Identification, assessment and treatment of women suffering from post traumatic stress after abortion. Journal of Family Psychotherapy, 5, 25-54.

Baker, A., Beresford, T., Halvorson-Boyd, G., \& Garrity, J. (1999). Informed consent, counseling, and patient preparation. In M. Paul, E. S. Lichtenberg, L. Borgatta, D. A. Grimes, \& P. G. Stubblefield (Eds.). A clinician's guide to medical and surgical abortion (pp. 25-37). New York: Churchill Livingstone.

Ballard, C., \& Prine, R. (2002). Citizen perceptions of community policing: Comparing Internet and mail survey responses. Social Science Computer Review, 20, 485-493.

Barnard, C. (1990). The long-term psychosocial effects of abortion. Jacksonville, FL: Institute for Pregnancy Loss.
Barnett, W., Freudenberg, N., \& Wille, R. (1992). Partnership after induced abortion: A prospective controlled study. Archives of Sexual Behavior, 2, 443-455.

Berger, J. (1994). The psychotherapeutic treatment of male homosexuality. American Journal of Psychotherapy, 48, 251-261.

Birnbaum, M. H. (2004). Human research and data collection via the internet. Annual Review of Psychology, 55, 803-832.

Blumberg, B. D., Golbus, M. S., \& Hanson, K. H. (1975). The psychological sequelae of abortion performed for a genetic indication. American Journal of Obstetrics and Gynecology, 122, 799-808.

Bracken, M. B. (1978). A causal mode of psychosomatic reactions to vacuum aspiration abortion. Social Psychiatry, 13, 135-145.

Bracken, M. B., Hachamovitch, M., \& Grossman, G. (1974). The decision to abort and psychological sequelae. Journal of Nervous and Mental Disease, 158, 154-162.

Bradshaw, Z., \& Slade, P. (2003). The effects of induced abortion on emotional experiences and relationships: A critical review of the literature. Clinical Psychological Review, 23, 929-958.

Bremner, J. D., Southwick, S. M., Johnson, D. R., Yehuda, R., \& Charney, D. S. (1993). Childhood physical abuse and combat-related posttraumatic stress disorder in Vietnam veterans. American Journal of Psychiatry, 150, 235-239.

Breslau, N., Davis, G. C., Andreski, P., \& Peterson, E. (1991). Traumatic events and posttraumatic stress disorder in an urban population of young adults. Archives of General Psychiatry, 48, 216-222.

Breslau, N., Schultz, L., \& Peterson, E. (1995). Sex differences in depression: A role of preexisting anxiety. Psychiatric Research, 58, 1-12.

Brewin, C. R., Andrews, B., \& Valentine, J. D. (2000). Metaanalysis of risk factors for posttraumatic stress disorder in trauma-exposed adults. Journal of Consulting and Clinical Psychology, 68, 748-766.

Broen, A., Moum, T., Bodtker, A. S., \& Ekeberg, O. (2004). Psychological impact on women of miscarriage versus induced abortion: A 2-year follow-up study. Psychosomatic Medicine, 66, 265-271.

Bryant, R. A., \& Harvey, A. G. (2003). Gender differences in the relationship between acute stress disorder and posttraumatic stress disorder following motor vehicle accidents. Australian and New Zealand Journal of Psychiatry, 37, 226-229.

Buchanan, M., \& Robbins, C. (1990). Early adult psychological consequences for males of adolescent pregnancy and its resolution. Journal of Youth and Adolescence, 19, 413-424.

Buchanan, T., \& Smith, J. L. (1999). Using the Internet for psychological research: Personality testing on the World Wide Web. British Journal of Psychology, 90, 125-144.

Burke, T., \& Reardon, D. (2002). Forbidden grief: The unspoken pain of abortion. Springfield, IL: Acorn Books.

Butterfield, M. I., Becker, M., \& Marx, C. E. (2002). Post-traumatic stress disorder in women: Current concepts and treatments. Current Psychiatry Reports, 4, 474-486.

Caplan, G. (1961). An approach to community mental health. New York: Grune \& Stratton. 
Coleman, P. K., \& Nelson, E. S. (1998). The quality of abortion decisions and college students' reports of post-abortion emotional sequelae and abortion attitudes. Journal of Social and Clinical Psychology, 17, 425-442.

Coleman, P. K., Reardon, D. C., Rue, V., \& Cougle, J. (2002). State-funded abortions vs. deliveries: A comparison of outpatient mental health claims over four years. American Journal of Orthopsychiatry, 72, 141-152.

Coleman, P. K., Reardon, D. C., Strahan, T. S., \& Cougle, J. R. (2005). The psychology of abortion: A review and suggestions for future research. Psychology and Health, 20, 237-271.

Coleman, P. K., Rue, V. M., Spence, M., \& Coyle, C. T. (2008). Abortion and the sexual lives of men and women: Is casual sexual behavior more common and more appealing after abortion? International Journal of Clinical and Health Psychology, 8, 77-91.

Cougle, J., Reardon, D. C., Coleman, P. K., \& Rue, V. (2005). Generalized anxiety associated with unintended pregnancy: A cohort study of the 1995 National Survey of Family Growth. Journal of Anxiety Disorders, 19, 137-142.

Cougle, J. R., Reardon, D. C., \& Coleman, P. K. (2003). Depression associated with abortion and childbirth: A long-term analysis of the NLSY cohort. Medical Science Monitor, 9, CR105-CR112.

Coyle, C. T. (2007). Men and abortion: A review of empirical reports. Internet Journal of Mental Health, 3, 1531-2941.

De Puy, C., \& Dovitch, D. (1997). The healing choice: Your guide to emotional recovery after an abortion. New York: Simon \& Schuster.

Duffy, E. (2000). Web-based research: An innovative method for nursing research. Journal of Canadian Oncology Nursing, 10, 45-49.

Fergusson, D. M., Horwood, L. J., \& Lynskey, M. T. (1996). Childhood sexual abuse and psychiatric disorders in young adulthood: Part II: Psychiatric outcomes of sexual abuse. Journal of the American Academy of Child and Adolescent Psychiatry, 35, 1365-1374.

Fergusson, D. M., Horwood, J., \& Ridder, E. M. (2006). Abortion in young women and subsequent mental health. Journal of Child Psychology and Psychiatry, 47, 16-24.

Foa, E. B. (1997). Trauma and women: Course, predictors and treatment. Journal of Clinical Psychiatry, 58, 25-28.

Gavranidou, M., \& Rosner, R. (2003). The weaker sex? Gender and posttraumatic stress disorder. Depression and Anxiety, 17, 130-139.

Gissler, M., Berg, C., Bouvier-Colle, M., \& Buekens, P. (2005). Injury deaths, suicides and homicides associated with pregnancy, Finland 1987-2000. European Journal of Public Health, 15, 459-463.

Gissler, M., Hemminki, E., \& Lonnqvist, J. (1996). Suicides after pregnancy in Finland, 1987-94: Register linkage study. British Medical Journal, 313, 1431-1434.

Gordon, R. A. (1978). Efficacy of a group crisis-counseling program for men accompanying women seeking abortions. American Journal of Community Psychology, 6, 239-246.
Gordon, R. A., \& Kilpatrick, C. (1977). A program of group counseling for men who accompany women seeking legal abortions. Community Mental Health Journal, 13, 291-295.

Gosling, S. D., Vazire, S., Srivastava, S., \& John, O. P. (2004). Should we trust Web-based studies? American Psychologist, 59, 93-104.

Guttmacher Institute. (2008, July). Facts on induced abortion in the United States. Retrieved September 30, 2008, from http://www .guttmacher.org/pubs/fb_induced_abortion.pdf

Hewson, C., \& Charlton, J. P. (2005). Measuring health beliefs on the Internet: A comparison of paper and Internet administrations of the Multidimensional Health Locus of Control Scale. Behavior Research Methods, 37, 691-702.

Holmes, M. C. (2004). Reconsidering a "woman's issue": Psychotherapy and one man's postabortion experiences. American Journal of Psychotherapy, 58, 103-115.

Jones, O. W., Penn, N. E., Shuchter, S., Stafford, C. A., Richards, T., Kernahan, C., et al. (1984). Parental response to mid-trimester therapeutic abortion following amniocentesis. Prenatal Diagnosis, 4, 249-256.

Kapfhammer, H. P., Rothenhausler, H. B., Krauseneck, T., Stoll, C., \& Schelling, G. (2004). Posttraumatic stress disorder and healthrelated quality of life in long-term survivors of acute respiratory distress syndrome. American Journal of Psychiatry, 161, 45-52.

Kero, A., Hogberg, U., \& Lalos, A. (2004). Well-being and mental growth: Long-term effects of legal abortion. Social Science \& Medicine, 58, 2559-2569.

Kero, A., \& Lalos, A. (2000). Ambivalence-a logical response to legal abortion: A prospective study among women and men. Journal of Psychosomatic Obstetrics and Gynecology, 21, 81-91.

Kero, A., \& Lalos, A. (2004). Reactions and reflections in men, 4 and 12 months post-abortion. Journal of Psychosomatic Obstetrics and Gynecology, 25, 135-143.

Kero, A., Lalos, A., Hogberg, U., \& Jacobsson, L. (1999). The male partner involved in legal abortion. Human Reproduction, 14, 2669-2675.

Kessler, R. C., Sonnega, A., Bromet, E., Hughes, M., \& Nelson, C. B. (1995). Posttraumatic stress disorder in the national comorbidity survey. Archives of General Psychiatry, 52, 1048-1060.

Knapp, H., \& Kirk, S. A. (2003). Using pencil and paper, Internet, and touch-tone phones for self-administered surveys: Does it really matter? Computers in Human Behavior, 19, 117-134.

Kraut, R., Olson, J., Banaji, M., Bruckman, A., Cohen, J., \& Couper, M. (2004). Psychological research online: Report of board of scientific affairs' advisory group on the conduct of research on the Internet. American Psychologist, 59, 105-117.

Kubany, E. S., Hill, E. E., \& Owens, J. A. (2003). Cognitive trauma therapy for battered women with PTSD: Preliminary findings. Journal of Traumatic Stress, 16, 81-91.

Kulka, R. A., Schlenger, W. E., Fairbank, J. A., Hough, R. L., Jordan, B. K., Marmar, C. R., et al. (1988). National Vietnam Veterans Readjustment Survey (NVVRS): Description, current status, and initial PTSD estimates. Research Triangle Park, NC: Research Triangle Institute. 
Lauzon, P., Roger-Achim, D., Achim, A., \& Boyer, R. (2000). Emotional distress among couples involved in first-trimester induced abortions. Canadian Family Physician, 46, 2033-2040.

Levine, S., Ancill, R. J., \& Roberts, A. P. (1989). Assessment of suicide risk by computer-delivered self-rating questionnaire: Preliminary findings. Acta Psychiatrica Scandinavica, 80, 216-220.

Locke, S. D., \& Gilbert, B. O. (1995). Method of psychological assessment, self-disclosure, and experiential differences: A study of computer, questionnaire, and interview assessment formats. Journal of Social Behavior and Personality, 10, 255-263.

Major, B., \& Cozzarelli, C. (1992). Psychological predictors of adjustment to abortion. Journal of Social Issues, 48, 121-142.

Major, B., Cozzarelli, C., Cooper, M. L., Zubek, J., Richards, C., Wilhite, M., et al. (2000). Psychological responses of women after first-trimester abortion. Archives of General Psychiatry, 57, 777-784.

Major, B., Cozzarelli, C., Sciacchitano, A. M., Cooper, M. L., Testa, M., \& Mueller, P. M. (1990). Perceived social support, self-efficacy and adjustment to abortion. Journal of Personality and Social Psychology, 59, 186-197.

Major, B., Richards, C., Cooper, M. L., Cozzarelli, C., \& Zubek, J. (1998). Personal resilience, cognitive appraisals, and coping: An integrative model of adjustment to abortion. Journal of Personality and Social Psychology, 74, 735-752.

Major, B., Zubek, J., Cooper, M., Cozzarelli, C., \& Richards, C. (1997). Mixed messages: Implications of social conflict and social support within close relationships for adjustment to a stressful life event. Journal of Personality and Social Psychology, 72, 1349-1363.

Mangan, M. A., \& Reips, U. (2007). Sleep, sex, and the Web: Surveying the difficult-to-reach population suffering from sexsomnia. Behavior Research Methods, 39, 223-236.

Marshall, R. D., Olfson, M., Hellman, F., Blanco, C., Guardino, M., \& Struening, E. L. (2001). Comorbidity, impairment, and suicidality in subthreshold PTSD. American Journal of Psychiatry, $158,1467-1473$.

Mathy, R. M., Schillace, M., Coleman, S. M., \& Berquist, B. E. (2002). Methodological rigor with Internet samples: New ways to reach underrepresented populations. Cyber Psychology and Behavior, 5, 253-266.

Mattinson, J. (1985). The effects of abortion on a marriage. Abortion: Medical Progress and Social Implications (Ciba Foundation Symposium S.), 115, 165-177.

Meyerson, P., \& Tryon, W. W. (2003). Validating internet research: A test of the psychometric equivalence of Internet and in-person samples. Behavior Research Methods, Instruments, \& Computers, 35, 614-620.

Moseley, D. T., Follingstad, D. R., Harley, H., \& Heckel, R. V. (1981). Psychological factors that predict reaction to abortion. Journal of Clinical Psychology, 37, 276-279.

Mufel, N., Speckhard, A., \& Sivuha, S. (2002). Predictors of posttraumatic stress disorder following abortion in a former Soviet Union country. Journal of Prenatal \& Perinatal Psychology and Health, 17, 41-61.
Myburgh, M., Gmeiner, A., \& van Wyk, S. (2001a). The experience of biological fathers of their partners' termination of pregnancy. Health SA Gesondheid, 6, 28-37.

Myburgh, M., Gmeiner, A., \& van Wyk, S. (2001b). Support for adult biological fathers during termination of their partners' pregnancies. Health SA Gesondheid, 6, 38-48.

National Abortion Federation. (2007). Clinical policy guidelines. Washington, DC: Author.

Naziri, D. (2007). Man's involvement in the experience of abortion and the dynamics of the couple's relationship: A clinical study. European Journal of Contraception and Reproductive Health Care, 12, 168-174.

O'Keefe, M. (1998). Posttraumatic stress disorder among incarcerated battered women: A comparison of battered women who killed their abusers and those incarcerated for other offenses. Journal of Traumatic Stress, 11, 71-85.

Osofsky, J. D., \& Osofsky, H. A. (1972). The psychological reaction of patients to legalized abortion. American Journal of Orthopsychiatry, 42, 48-60.

Owings, M. F., \& Kozak, L. J. (1996). Ambulatory and inpatient procedures in the United States, 1996. Vital and Health Statistics, 13(139), 1-119.

Payne, E., Kravitz, A., Notman, M., \& Anderson, J. (1976). Outcome following therapeutic abortion. Archives of General Psychiatry, 33, 725-733.

Pedersen, W. (2007). Addiction, childbirth, abortion and subsequent substance use in young women: A population-based longitudinal study. Addiction, 102, 1971-1978.

Pedersen, W. (2008). Abortion and depression: A population-based longitudinal study of young women. Scandinavian Journal of Public Health, 36, 424-428.

Peters, L., Issakidis, C., Slade, T., \& Andrews, G. (2006). Gender differences in the prevalence of DSM-IV and ICD-10 PTSD. Psychological Medicine, 36, 81-89.

Petit, F. A. (2002). A comparison of World Wide Web and paperand-pencil personality questionnaires. Behavior Research Methods, Instruments, \& Computers, 34, 50-54.

Poggenpoel, M., \& Myburgh, C. P. H. (2002). The developmental implications of a termination of pregnancy on adolescents with reference to the girl and her partner. Education, 122, 731-831.

Reardon, D. C., Coleman, P. K., \& Cougle, J. (2004). Substance use associated with prior history of abortion and unintended birth: A national cross sectional cohort study. American Journal of Drug and Alcohol Abuse, 26, 369-383.

Reardon, D. C., \& Cougle, J. (2002). Depression and unintended pregnancy in the National Longitudinal Survey of Youth: A cohort study. British Medical Journal, 324, 151-152.

Reardon, D. C., Cougle, J., Rue, V. M., Shuping,:M., Coleman, P. K., \& Ney, P. G. (2003). Psychiatric admissions of low-income women following abortion and childbirth. Canadian Medical Association Journal, 168, 1253-1256.

Rees, D. I., \& Sabia, J. J. (2007). The relationship between abortion and depression: New evidence from the Fragile Families and Child Wellbeing Study. Medical Science Monitor, 13, 430-436. 
Reich, J. A., \& Brindis, C. D. (2006). Conceiving risk and responsibility: A qualitative examination of men's experiences of unintended pregnancy and abortion. International Journal of Men's Health, 5, 133-152.

Reips, U. (2000). The Web experiment method: Advantages, disadvantages, and solutions. In M. H. Birnbaum (Ed.), Psychological experiments on the Internet (pp. 89-117). San Diego, CA: Academic Press.

Richman, W., Kiesler, S., Weisb, S., \& Drasgow, F. (1999). A meta-analytic study of social desirability distortion in computeradministered questionnaires, traditional questionnaires, and interviews. Journal of Applied Psychology, 84, 754-775.

Robie, C., \& Brown, D. J. (2006). Measurement equivalence of a personality inventory administered on the Internet via a kiosk. Applied H.R.M. Research, 11, 97-106.

Robson, F. M. (2002). "Yes! A chance to tell my side of the story": A case study of a male partner of a woman undergoing termination of pregnancy for foetal abnormality. Journal of Health Psychology, 7, 183-193.

Rothstein, A. (1977a). Abortion: A dyadic perspective. American Journal of Orthopsychiatry, 47, 111-118.

Rothstein, A. (1977b). Men's reactions to their partners' elective abortions. American Journal of Obstetrics and Gynecology, 128, 831-837.

Rue, V. M., Coleman, P. K., Rue, J. J., \& Reardon, D. C. (2004). Induced abortion and traumatic stress: A preliminary comparison of American and Russian women. Medical Science Monitor, 10, SR5-SR16.

Sareen, J., Houlahan, T., Cox, B. J., \& Asmundson, G. J. (2005). Anxiety disorders associated with suicidal ideation and suicide attempts in the National Comorbidity Survey. Journal of Nervous and Mental Disease, 193, 450-454.

Schilling, E. A., Aseltine, R. H., \& Gore, S. (2007). Adverse childhood experiences and mental health in young adults: A longitudinal survey. BMC Public Health, 7, 30.

Schmidt, W. (1997). World-Wide Web survey research: Benefits, potential problems, and solutions. Behavior Research Methods, Instruments, \& Computers, 29, 274-279.

Schnurr, P. P., Hayes, A. F., Lunney, C. A., McFall, M., \& Uddo, M. (2006). Longitudinal analysis of the relationship between symptoms and quality of life in veterans treated for posttraumatic stress disorder. Journal of Consulting and Clinical Psychology, 74, 707-713.

Shalev, A. Y. (2001). What is posttraumatic stress disorder? Journal of Clinical Psychiatry, 62(Suppl. 17), 4-10.

Shostak, A. (1979). Abortion as fatherhood lost: Problems and reforms. The Family Coordinator, 28, 569-574.

Shostak, A. (1983). Men and abortion: Three neglected ethical aspects. Humanity and Society, 7, 66-85.

Shostak, A. (2007). Men, me and abortion: On doing the right thing. Men and Masculinities, 10, 360-366.

Shostak, A., \& McLouth, G. (1984). Men and abortion: Lessons, losses, and love. New York: Praeger.

Singer, J. (2004). Options counseling: Techniques for caring for women with unintended pregnancies. Journal of Midwifery \& Women's Health, 49, 235-242.
Skitka, L. J., \& Sargis, E. G. (2006). The Internet as psychological laboratory. Annual Review of Psychology, 57, 529-555.

Smith, M. A., \& Leigh, B. (1997). Virtual subjects: Using the internet as an alternative source of subjects and research environment. Behavior Research Methods, Instruments, \& Computers, 29, 496-505.

Soderberg, H., Janzon, L., \& Sojberg, N. O. (1998). Emotional distress following induced abortion: A study of its incidence and determinants among abortees in Malmo, Sweden. European Journal of Obstetrics and Gynecology and Reproductive Biology, 79, 173-178.

Speckhard, A. (1987). Psycho-social stress following abortion. Kansas City, MO: Sheed \& Ward.

Speckhard, A., \& Rue, V. (1993). Complicated mourning: Dynamics of impacted post-abortion grief. Journal of Pre- and Perinatal Psychology, 8, 5-32.

Steinberg, J., \& Russo, N. (2008). Abortion and anxiety: What's the relationship? Social Science \& Medicine, 67, 238-252.

Steinberg, T. N. (1989). Abortion counseling: To benefit maternal health. American Journal of Law \& Medicine, 15, 483-517.

Stites, M. C. (1982). Decision making model of pregnancy counseling. Journal of American College Health, 30, 244-247.

Suliman, S., Ericksen, T., Labuschgne, P., de Wit, R., Stein, D. J., \& Seedat, S. (2007). Comparison of pain, cortisol levels, and psychological distress in women undergoing surgical termination of pregnancy under local anaesthesia versus intravenous sedation. BMC Psychiatry, 7, 1-9.

Thorp, J., Hartman, K., \& Shadigan, E. (2003). Long-term physical and psychological health consequences of induced abortion: Review of the evidence. Obstetrical and Gynecological Survey, 58, 67-79.

Torre-Bueno, A. (1996). Peace after abortion. San Diego, CA: Pimpernel Press.

Walsh, J. P., Kiesler, S., Sproull, L. S., \& Hesse, B. W. (1992). Selfselected and randomly selected respondents in a computer network survey. Public Opinion Quarterly, 56, 241-244.

Warshaw, M. G., Fierman, E., Pratt, L., Hunt, M., Yonkers, K. A., Massion, A. O., et al. (1993). Quality of life and dissociation in anxiety disorder patients with histories of trauma or PTSD. American Journal of Psychiatry, 150, 1512-1516.

Weathers, F. W., Litz, B. T., Herman, D. S., Huska, J. A., \& Keane, T. M. (1993, October). The PTSD Checklist: Reliability, validity, and diagnostic utility. Paper presented at the annual meeting of the International Society for Traumatic Stress Studies, San Antonio, TX.

White-van Mourik, M. C., Connor, J. M., \& Ferguson-Smith, M. A. (1992). The psychological sequelae of a second-trimester termination of pregnancy for abnormality. Prenatal Diagnosis, 12, 189-204.

Wilmoth, G., deAlteriis, M., \& Bussell, D. (1992). Prevalence of psychological risks following legal abortion in the U.S.: Limits of the evidence. Journal of Social Issues, 48, 37-66.

Wilson, R. (2003). The Internet makes gathering data quick, easy, and cheap. Nursing Standard, 18, 20.

Yeaworth, R. (2001). Use of the Internet in survey research. Journal of Professional Nursing, 17, 187-193. 
Zavodny, M. (2001). The effect of partners' characteristics on teenage pregnancy and its resolution. Family Planning Perspectives, 33, 192-199; 205.

Zolese, G., \& Blacker, C. V. (1992). The psychological complications of therapeutic abortion. British Journal of Psychiatry, 160, 742-749.

\section{Bios}

Dr. Coyle is a co-director of the Alliance for Post-Abortion Research \& Training, Inc. Her research interests include the psychological effects of abortion on men and the psychology of forgiveness.
Dr. Coleman is an Associate Professor of Human Development and Family Studies at Bowling Green State University. Her current research focuses on women's responses to induced abortion including mental health (anxiety, depression, suicide ideation), substance abuse, intimate partner relationship issues, and parenting.

Dr. Rue is the director of the Institute for Pregnancy Loss in Jacksonville, FL. For 35 years he has treated women and men who have experienced abortion as traumagenic and is an active litigation consultant. 